\title{
Arctic Ocean manganese contents and sediment colour cycles
}

\author{
Ludvig Löwemark, Martin Jakobsson, Magnus Mörth \& Jan Backman \\ Department of Geology and Geochemistry, Stockholm University, SE-106 91 Stockholm, Sweden
}

\begin{abstract}
Keywords
manganese; Mn; colour cycles; ventilation cycles; Arctic Ocean.

\section{Correspondence}

L. Löwemark, Department of Geology and Geochemistry, Stockholm University, SE-106 91 Stockholm, Sweden.

E-mail: loewemark@gmail.com
\end{abstract}

doi:10.1111/j.1751-8369.2008.00055.x

\begin{abstract}
Cyclical variations in colour and manganese content in sediments from the central Arctic Ocean have been interpreted to represent climatically controlled changes in the input of $\mathrm{Mn}$ from the Siberian hinterland, and/or variations in the intermediate and deep water ventilation of the Arctic basins, although a diagenetic origin has not been excluded. A reinvestigation of core 96/12-1pc using an Itrax X-ray fluoresence (XRF) core scanner confirms that these colour cycles are indeed controlled by variations in $\mathrm{Mn}$ content, although changes in the source region of the sediment may override the Mn colour signal in certain intervals. The prominent $\mathrm{Mn}$ cycles show no correspondence to any of the other measured elements. This decoupling of Mn and the bulk chemistry of the sediment is taken to indicate that the cycles observed are caused by variations in water column ventilation and riverine input, rather than variations in sediment source or diagenesis. We therefore conclude that the Mn maxima do represent warm phases with increased ventilation and/or riverine input, and that they therefore could be used for chronostratigraphic correlation between cores from the central Arctic Ocean, where traditional isotope stratigraphy is difficult or impossible to establish because of the lack of calcareous microfossils.
\end{abstract}

Many cores raised from the central Arctic Ocean are characterized by pronounced sequential variation in sediment colour and solid-phase manganese content (Li et al. 1969; Jakobsson et al. 2000; Spielhagen et al. 2004). These changes in Mn contents and colour properties have been interpreted to represent glacial-interglacial variability, and to mimic lower latitude $\delta^{18} \mathrm{O}$ amplitude changes, to the extent that marine isotope stages (MIS) were assigned to the sediment cycles in order to constrain Arctic Ocean Pleistocene chronology (Jakobsson et al. 2000). They attributed the mechanism for the observed variability to either one of the following two processes, or to a combination of both: contrasts in ventilation of Arctic Ocean intermediate and deep waters during glacial-interglacial cycles, thereby leading to increased oxygenation, and subsequently to $\mathrm{Mn}$ precipitation during interglacials and interstadials; the rivers of northern Siberia, draining extensive peat and bog areas, operate in an on-off mode tuned to glacial-interglacial conditions, thereby leading to a higher output of Mn during interglacials and interstadials. Both these solutions imply that exogenetic palaeoenvironmental changes directly caused the observed differences in Mn concentration, and that glacial-interglacial cyclicity was the underlying driving mechanism for the observed concentration changes.

The usefulness of the Arctic Ocean Mn colour cycles as a potential palaeoceanographic indicator of past glacialinterglacial changes in redox conditions thus relies on the assumption that the diagenetic processes leading to solidphase Mn precipitation occur at, or near, the sedimentwater interface, rather than deeper in the sediment column. Preliminary results from pore water analysis of the Arctic Coring Expedition (ACEX) sediments from the Lomonosov Ridge in the central Arctic Ocean show a clear trend of increasing contents of dissolved Mn between ca. 50 and $20 \mathrm{~m}$ stratigraphic depth, followed by another trend of clearly decreasing contents from ca. $20 \mathrm{~m}$ to the sediment-water interface (Dickens et al. 2007). The sample spacing depicting these trends is not sufficiently resolved in order to capture glacial-interglacial variability. Still, these pore water results raise the question of whether or not the Mn concentration profiles are driven by post-depositional processes, and hence are formed by local geochemical conditions in the sediment column, rather than reflecting the influence of palaeoclimatic variability at the sediment-water interface. 


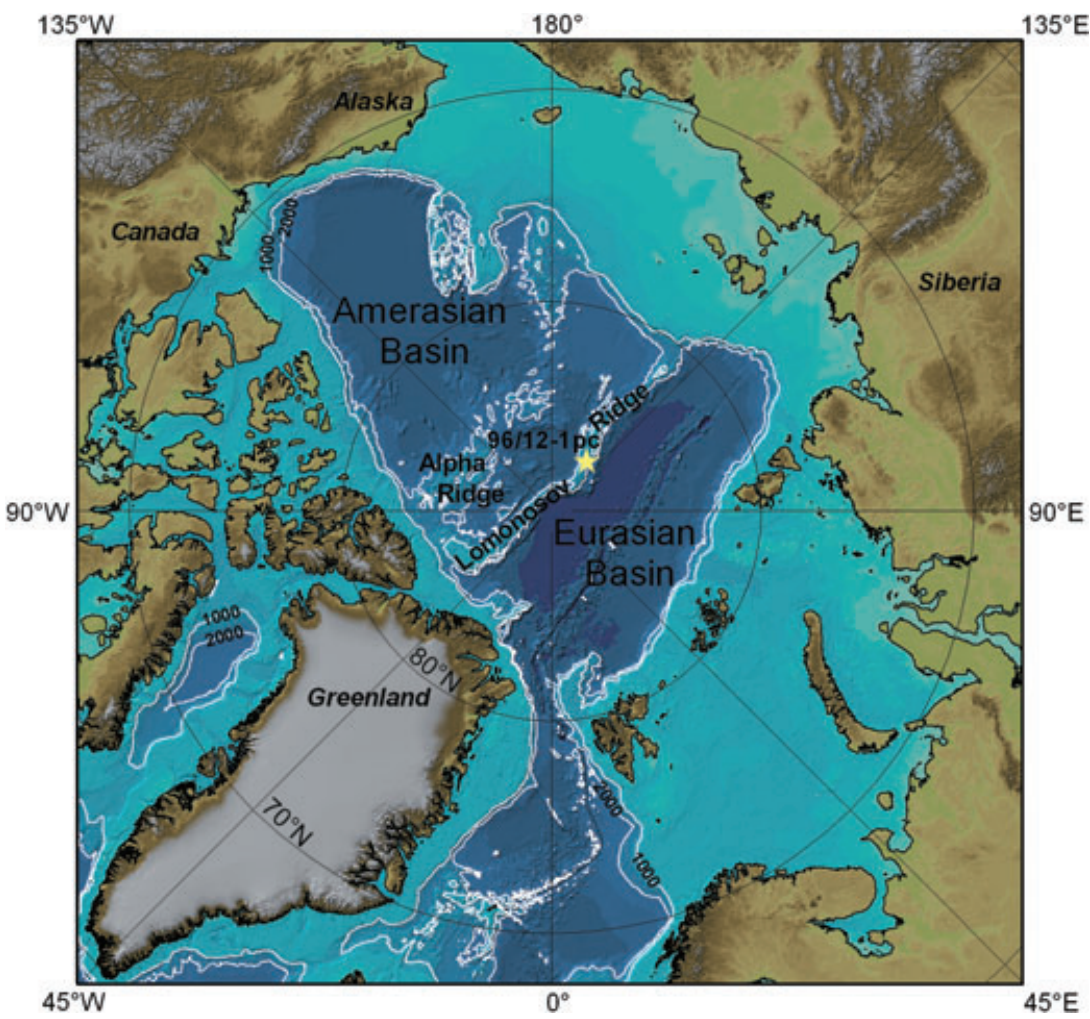

Fig. 1 Bathymetric map showing the location of core 96/12-1pc on the Lomonosov Ridge in the central Arctic Ocean.
Here, we use X-ray fluorescence (XRF) core scanning to reinvestigate a key piston core $(96 / 12-1 p c)$ from the Lomonosov Ridge (Fig. 1), which contains a strong correlation between the solid-phase $\mathrm{Mn}$ content measured in bulk sediment samples and the sediment colour (Jakobsson et al. 2000). The XRF scanner provides major element data ranging from $\mathrm{Al}$ to $\mathrm{U}$, allowing us to further address the nature of the Mn colour cycles and their usefulness as a palaeoceanographic proxy. In addition, these data permit us to re-evaluate the transfer function developed by Jakobsson et al. (2000), which was originally used to estimate Mn content from extracted red, green and blue values from a digital RGB image of core 96/12-pc. The main purpose of this study has been to further explore if the prominent $\mathrm{Mn}$ and colour cycles in many central Arctic Ocean sediment cores can be used as a proxy for glacial-interglacial variability.

\section{Methods and materials}

Core 96/12-1pc was retrieved from the crest of the Lomonosov Ridge $\left(87^{\circ} 05.9^{\prime} \mathrm{N}, 144^{\circ} 46.4^{\prime} \mathrm{E}, 1003 \mathrm{~m}\right.$ water depth; Fig. 1) (Jakobsson et al. 2000). Although geophysical mapping has shown that the ridge crest has been subjected to glacial ice erosion, dated to MIS 6 (Jakobsson et al. 2001; Polyak et al. 2001), close to core 96/12-1pc, this core was raised from water depths slightly deeper than the deepest mapped ice erosion. Thus, this core contains an apparently undisturbed palaeoceanographic record extending beyond MIS 6. Calcareous nannofossil biostratigraphy, using Emiliania huxleyi and Gephyrocapsa spp., helped identify MIS 1 and MIS 5.1, 5.3 and 5.5 (Jakobsson et al. 2000). A neighbouring core that has been correlated with 96/12-1pc using several distinct grain-size changes has been dated using optically stimulated luminescence. The results from 11 samples support the assignment of the biostratigraphically derived MIS 5.1-5.5 in core 96/12-1pc (Jakobsson et al. 2003).

The archive halves of core 96/12-1pc were measured using the Itrax XRF scanner in the core processing laboratory at Stockholm University (for a detailed description of the Itrax core scanner, see Croudace et al. 2006). The X-ray tube used was a Mo-tube (PANalytical, http:// www.panalytical.com) operated at $30 \mathrm{kV}$ and $30 \mathrm{~mA}$. The sediment core was measured continuously over $5 \mathrm{~mm}$ intervals with a 10-s exposure time. This rather short exposure gives a relatively high noise level in $\mathrm{Al}$, but reliable data for most elements above $\mathrm{Al}$, implying that Mn is well above the threshold for noisy measurements. The XRF measuring spot in the Itrax scanner is $4 \mathrm{~mm}$ wide. With a step length of $5 \mathrm{~mm}$, the chemical elements are integrated over $4 \times 5-\mathrm{mm}^{2}$ areas. This will be referred to as data with $5-\mathrm{mm}$ resolution. Previous discrete bulk measurements of Mn content from the core (Jakobsson 
et al. 2000) were used to calibrate the obtained Itrax Mn counts into Mn concentrations.

The Itrax XRF-scanner offers a fast and non-destructive way of analysing elements from $\mathrm{Al}$ to $\mathrm{U}$, with detection limits generally in the ppm to per mil range, directly from split core halves, and thus presents an extremely efficient way of obtaining basic sediment geochemical information and guides further analysis.

Although XRF scanning is non-destructive, care must be taken to prevent drying out the core, resulting in shrinkage and formation of cracks. In contrast to the Eagle II BKA system (Haschke 2006), which cools the sample chamber in order to prevent drying the core, the Itrax system requires that a thin foil $(1.5-\mu \mathrm{m}$ thick; Chemplex, http://www.chemplex.com) be applied directly to the sediment surface. This procedure is standard for the Itrax XRF scanner, but has been shown to result in the formation of a thin water film between the sediment and the foil. This artificially reduces the intensities of lighter elements such as Al and Si (Tjallingii et al. 2007). Measured XRF intensities may also be biased by absorption of XRF in the air between the sample surface and the detector. The Itrax solves this problem by attaching a vacuum-filled nozzle in front of the XRF detector. However, this still leaves a short air-filled distance between the nozzle and the sample surface that must be corrected for in the post-processing of the measured intensities. The software used was Q-SPEC, provided by the Itrax manufacturer. Other solutions to prevent the absorption of XRF in the air include flushing the entire measuring chamber with $\mathrm{He}$, as performed in the AAVATECH XRF core scanner (Richter et al. 2006).

The Itrax XRF scanner measures fluorescence intensities resulting from exposing the sediment surface to $\mathrm{X}$-ray radiation of a certain energy spectrum. Because the resulting XRF is dependent on several factors, such as surface texture, water content and sample matrix, the retrieved data are inherently semi quantitative (Richter et al. 2006). To obtain true element concentrations, individual calibration sets would have to be developed for each core section and each sediment type. Nevertheless, as shown in the results section, the obtained data give extremely detailed information about the relative variations in the elements, and by tying these variations to known concentrations, semi-quantitative concentration variations can also be obtained.

\section{Results}

Variations in Mn content established by the Itrax scanner match almost perfectly with the previously measured Mn concentrations of discrete bulk sediment samples using inductively coupled plasma atomic emission spectroscopy
(ICP-AES), thus allowing a calibration of the XRF values into Mn concentrations (Figs. 2, 3). Discrepancies are primarily found where the Itrax data show larger short-term variability: variations that are likely to be smoothed by the larger sample size of the bulk measurements. Whereas the bulk measurements were performed on homogenized samples with a volume of $6.2 \mathrm{~cm}^{3}$, and a stratigraphic resolution of $2 \mathrm{~cm}$ (Jakobsson et al. 2000), the Itrax measurements were performed with a resolution of $0.5 \mathrm{~cm}$ from the surface of the sample. It is therefore not surprising that some of the narrower peaks measured by the Itrax are not present in the bulk measurements.

The most striking feature of the variations in $\mathrm{Mn}$ obtained from the Itrax scanner is the strong similarity to the Mn values calculated by Jakobsson et al. (2000) from the RGB values derived from a digital core image. A conspicuous mismatch between the RGB and Itrax results occurs in a distinct grey layer between 113 and $164 \mathrm{~cm}$. In this layer, the RGB transfer function estimates $\mathrm{Mn}$ concentrations up to over $1.5 \%$, whereas both Itrax data and bulk measurements show Mn concentrations at a distinct minimum over the entire interval. Other areas where discrepancies are found include the topmost and lowermost parts of the core, where the Itrax data show significantly higher peak values at several locations. There is also a strong peak in the RGB-derived Mn value at around $650 \mathrm{~cm}$ that completely lacks a counterpart in the Itrax record. As Mn variations obtained through the RGB transfer function have not been measured from exactly the same strip as the XRF data, some of the smaller differences between the two techniques are likely to result from small-scale spatial variability of the sample surface.

The prominent cycles observed in Mn concentration are not present in any other measured element, as indicated by multiple regression analysis (Table 1). However, several elements, such as $\mathrm{Fe}, \mathrm{Ti}, \mathrm{K}$ and $\mathrm{Si}$, show large variations with expressed peaks at certain levels. This is particularly conspicuous in the grey layer, where Fe and Ti show an anomaly with low respective high values. It is interesting to note that despite the fact that there is no statistical correlation between most of the elements, there are a number of event-like excursions that are reflected by most elements, for example, the excursion in Fe, Ti, K and Si around $480 \mathrm{~cm}$ (Fig. 2). Moreover, these variations appear to be completely decoupled from the Mn cycles. A few elements, for example $\mathrm{K}$ and $\mathrm{Al}$, show moderately strong covariation with $\mathrm{Si}$. This relationship may be explained by variations in the abundance of feldspars in the dominantly siliciclastic sediments. Other elements do not appear to be correlated or anticorrelated (Table 1). 


\section{-}




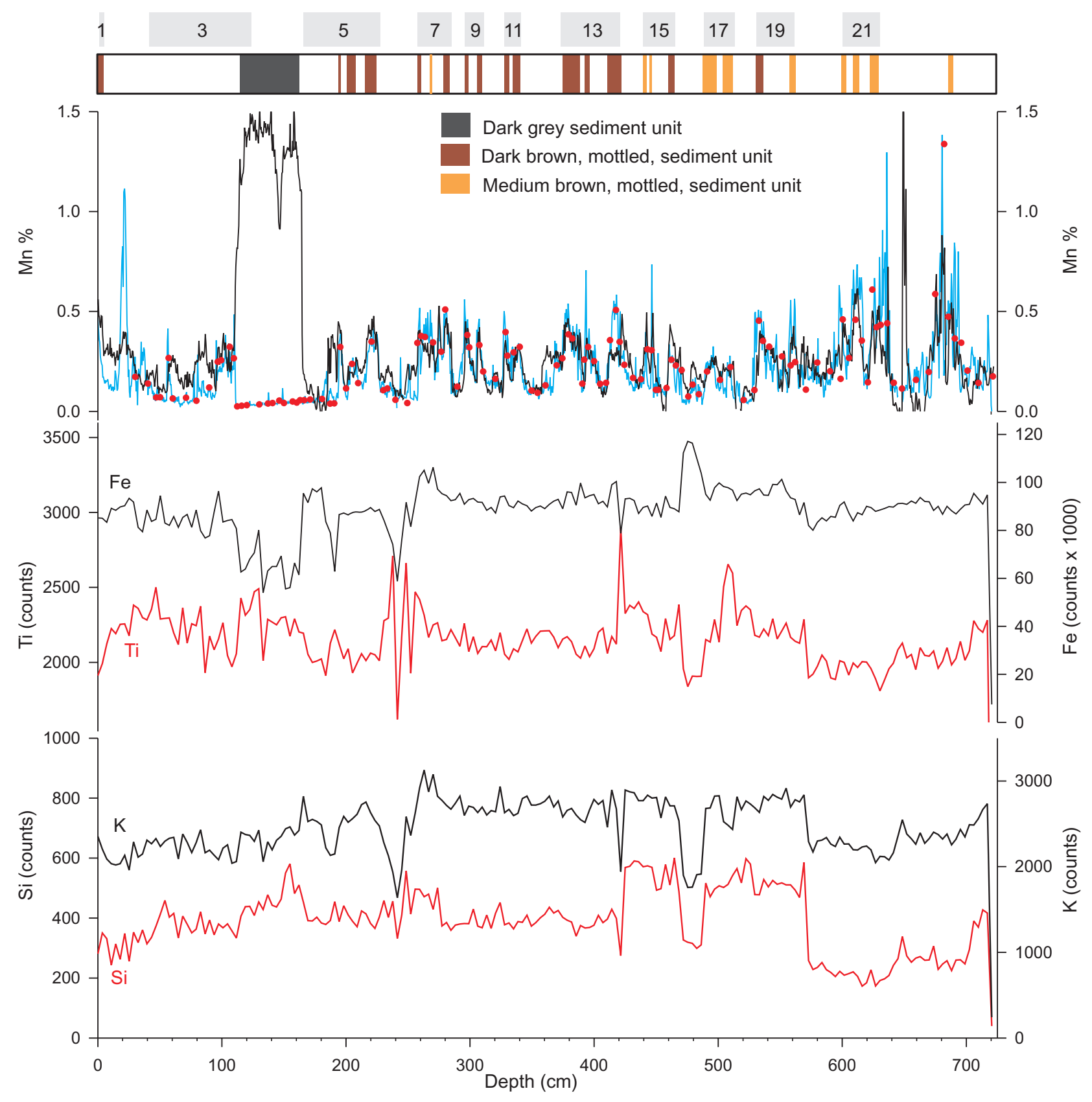

Fig. 2 Lithostratigraphy and Mn concentrations obtained using the red, green and blue (RGB) transfer function (black line), X-ray fluoresence (XRF) (blue line) and discrete measurements on bulk sediment using inductively coupled plasma atomic emission spectroscopy (ICP-AES) (red dots) compared with selected elements and the age model of Jakobsson et al. (2000). A running mean is applied to the Mn calculated from RGB values and XRF values of Fe, $\mathrm{Ti}, \mathrm{K}$ and $\mathrm{Si}$. Grey bars at the top denote the interglacial marine isotope stages.

\section{Discussion}

The focus of this study was to further investigate whether $\mathrm{Mn}$ and colour cycles in central Arctic Ocean sediment cores are in phase with lower latitude $\delta^{18} \mathrm{O}$ amplitude variations, hence representing glacial-interglacial variability, as was suggested by Jakobsson et al. (2000). Can variations in elements other than $\mathrm{Mn}$ be used to differentiate between the relative importance of ocean ventilation vs. riverine input, and can they also tell us something about the potential influence of diagenetic processes in the formation and preservation of the prominent Mn cycles that appear to be widespread in the Arctic Basin? 


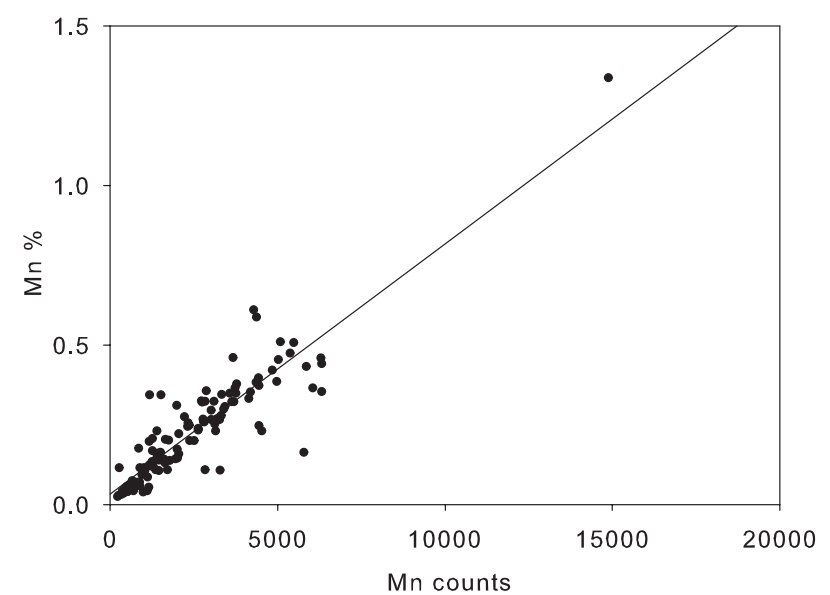

Fig. 3 Calibration of the X-ray fluoresence (XRF) counts, measured by the Itrax scanner into concentrations using discrete samples, with a resolution of $2 \mathrm{~cm}$.

The XRF data of the scanned core 96/12-pc are consistent with previous estimates of Mn contents based on sediment colour and previous bulk measurements using ICP-AES (Figs. 2, 3), except for a 51 -cm interval, in which the RGB transfer function yields incorrect Mn concentrations. Not surprisingly, the high-resolution XRF data reveal shorter term and more abrupt larger amplitude variations in Mn compared with the data acquired from discrete sample measurements of bulk sediment. Our datasets demonstrate that Itrax counts can be successfully calibrated to absolute concentrations (Fig. 2). The generally strong correlation between the Mn concentrations obtained from the RGB transfer function and the data from the XRF measurements demonstrate that under most conditions, the colour of the sediment is primarily controlled by variations in Mn content. This is corroborated by the fact that no other element correlates with Mn. Whereas $\mathrm{Mn}$ is supplied to the Arctic Ocean in dissolved and particulate form by riverine input or hydrothermal activities, most other elements are supplied to the sediment by ice rafting from the source regions on the shelves. Consequently, variations in Mn are fundamentally decoupled from most other elements. However, the total collapse of the correlation between sediment colour, RGB reconstructed Mn values and the actual Mn concentrations in the $51-\mathrm{cm}$-thick grey layer show that under certain circumstances, changes in sediment composition can override $\mathrm{Mn}$ as the colour-controlling factor. Large changes in major elements in the grey layer, such as in $\mathrm{Fe}$ and $\mathrm{Ti}$, suggest a major reorganization of either source areas or ice drift delivering sediment to the central Arctic Ocean. It should be noted that the grey layer in core 96/12-1pc in fact represents one of the most conspicuous features in the eastern central Arctic Ocean found in a suite of studied sediment cores (Spielhagen et al. 2004). The grey layer is primarily composed of icerafted debris (IRD). It has been assigned an age of MIS 4 and has been suggested to represent a prominent advance of the Barents-Kara ice sheet (Spielhagen et al. 2004). The origin and genesis of the grey layer, however, is beyond the scope of this study.

From the above discussion we can conclude that under background conditions, the sediment colour is controlled by $\mathrm{Mn}$, and only in event horizons, where background sedimentation is disrupted, may the input of foreign material play any significant role in the colour of the sediment. We can therefore exclude variations in sediment source and transport paths as controlling Mn cycles in the sediment, but can the new results be used to differentiate between the importance of post-depositional diagenesis, bottom water ventilation and riverine Mn input? One potential pitfall regarding the interpretation that the individual Mn and colour cycles in the Arctic Ocean are related to glacial-interglacial variations, and are thus linked to low-latitude $\delta^{18} \mathrm{O}$ amplitude variations, is the potential for multiple peaks to be attributed to nonsteadystate redox cycling of Mn (Wilson et al. 1986; Dhakar \& Burdige 1996). A diagenetic formation of multiple Mn peaks will develop if, for example, the migration rate of $\mathrm{Mn}^{2+}$ equals the sedimentation rate. Then the redox boundary will move upwards at the same rate, and Mn oxide peaks will be formed just above this boundary. The redox boundary may also move upwards and downwards, depending on oxygen concentration (Dhakar $\&$ Burdige 1996; Mangini et al. 2001). The possible importance of variations in the redox potential boundary in Arctic sediments is illustrated by the dissolved metal concentration profiles of $\mathrm{Mn}$ and Fe in the adjacent, over 400-m long, ACEX section from the central Lomonosov Ridge. In this section, Mn and Fe show characteristic trends, i.e., high Mn concentrations between 1.5 and 80 metre composite depth (mcd), centred at 20 mcd, and high Fe concentrations, between 20 and $200 \mathrm{mcd}$, centred at $80 \mathrm{mcd}$ (Dickens et al. 2007). This implies Mn oxide reduction followed by Fe oxide reduction, and diffusion of dissolved Mn and Fe upwards and downwards, depending on the redox front for each element. In the deeper parts of the ACEX sediments, pore water data suggest that sulphate reduction is important (Backman et al. 2006). On the other hand, it has also been shown that the oxygen concentration in the pore water is anti-correlated with the organic carbon flux to the bottom sediments (Finney et al. 1988). In the ACEX sediments, the variation in organic carbon content is rather low, varying between 0.2 and $0.4 \%$ in the upper $190 \mathrm{~m}$ (Backman et al. 2006), and thereby the expected variability in pore water oxygenation is also rather small. Another argument against 


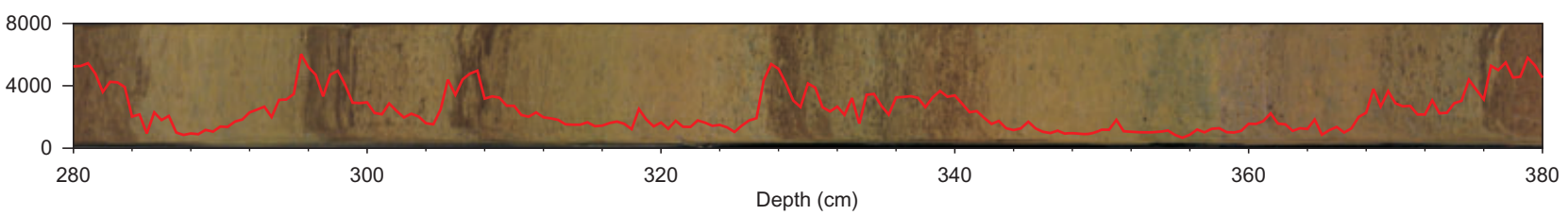

Fig. 4 Digital photograph of a core section from core 96/12-pc showing distinct colour cycles. The red curve shows the variations in Mn measured by the Itrax XRF scanner. Maxima in Mn clearly correspond to brown, bioturbated layers.

diagenesis comes from the lack of covariation between $\mathrm{Mn}$ and other redox-sensitive elements. Elements such as $\mathrm{U}$, Fe and $\mathrm{V}$ would be expected to follow Mn variations in phase or antiphase if post-sedimentary diagenetic processes played an important role in the formation of the Mn cycles (Thomson et al. 1996). One further argument against a diagenetic origin of the Mn peaks is their relatively narrow spacing. With only $20-30 \mathrm{~cm}$ between peaks with a width of ca. $5 \mathrm{~cm}$, it is difficult to visualize that a migration of $\mathrm{Mn}^{2+}$ in between two peaks would mobilize enough Mn to produce peaks with a general Mn concentration of ca. $0.5 \%$ above the background in the time span between the two oxidation events.

In the case that the deposition of Mn layers is controlled by environmental factors rather than by redox reactions in the sediment, this implies that they are synchronous with glacial-interglacial variations, and thus can be correlated with the low-latitude isotope record, which would provide a major advance in the general age control of Arctic core material. Supporting synchrony is the co-occurrences of calcareous microfossils indicative of interglacial stages MIS 1 and MIS 5 in the two uppermost brown, commonly bioturbated, Mn-enriched sediment cycles, which are separated by non-carbonate bearing, sparsely bioturbated, Mn-poor glacial stage sediments (Jakobsson et al. 2000). Biogenic carbonate is, however, not generally preserved below MIS 5 . Consequently, prior to MIS 5, intervals with elevated Mn contents cannot be tied to influxes of carbonate producing plankton, which are assumed to represent interglacial conditions. The problem of carbonate dissolution makes this line of evidence for synchrony less conclusive. On the other hand, as more vigorous bioturbation is interpreted to represent less severe sea-ice coverage, oxygenation of deeper waters and hence interglacial conditions, the Mn-rich intervals below MIS 5 should also represent interglacial conditions (Fig. 4).

Mn variations thus appear to be decoupled from the main sediment geochemistry because the bulk sediment is delivered by ice rafting, whereas Mn is supplied to the basin in dissolved form by river and hydrothermal input. Most other river-delivered elements occur in such small concentrations that the river input is negligible in com- parison with the enormous reservoirs of the Arctic Ocean. Consequently, variations in other elements unfortunately cannot be used to separate the relative importance of riverine $\mathrm{Mn}$ input vs. water column ventilation. To differentiate between the importance of riverine Mn input and ventilation, Mn budget calculations are needed that show how large the $\mathrm{Mn}$ input by rivers are in relation to the total $\mathrm{Mn}$ precipitated during interglacial times. However, the spatial coverage of sediment samples in the Arctic Basin is too low to permit accurate estimates, and variability in river input and river water Mn content also contain substantial uncertainties.

The lack of correlation with other redox-sensitive elements, for example $\mathrm{Fe}, \mathrm{U}$ and $\mathrm{V}$, in the sediment is puzzling, as they would be expected to covary with Mn if redox processes in the water column (ventilation) or sediment were the main driving force behind the observed cyclicity. This could be interpreted as indirect support for the river-input hypothesis proposed by Jakobsson et al. (2000). However, the analytical precision of the Itrax XRF scanner, using only 10-s exposure time, is perhaps not good enough to permit conclusions to be drawn from the data of some of the minor trace elements.

Although the bioturbation indicating ventilated bottom waters can be used as an argument for synchrony, marking interglacial conditions, the bioturbation in itself may also constitute a problem by its smearing and smoothing effect on the sedimentary record (Berger $\&$ Heath 1968; Schiffelbein 1984). Input Mn events may be preserved in the sediment if they occur at a certain frequency and are large enough in magnitude, otherwise the input events would be dampened or completely smeared out by diffusion (Lasaga \& Holland 1974). Following the discussion by Burdige (2006), who suggested that if half of the input period is greater than the age of the mean mixed layer, then the input will not be dampened out, the mean mixed layer age in this sediment can be estimated by dividing the mixed layer depth $(\mathrm{ca} .4 \mathrm{~cm})$ with the sedimentation rate (assuming $0.002 \mathrm{~cm}$ per year for central Arctic Ocean sediments), i.e., 4/0.002 = 2000 years. The input period must therefore be at least 4000 years to be preserved. However, it is evident from this relationship that lower sedimentation rates will result in 
longer input periods needed to record an input event. This is an important consideration if the Mn colour cycles are to be used for chronostratigraphic correlations between cores from different regions with different sedimentation rates. If the brown Mn-enriched cycles in the Arctic Ocean indeed represent interglacials, a duration on the order of $10 \mathrm{Ky}$ is expected for each interglacial (Forsström 2001; Lisiecki \& Raymo 2005). Bioturbation and diffusion therefore does not pose any substantial problem for the preservation of the Mn peaks in the studied core, although they may have been reduced in amplitude (Anderson 2001).

\section{Conclusions and perspectives}

The re-evaluation of core 96/12-1pc using an Itrax XRF core scanner allows a number of conclusions to be drawn. - The RGB colour transfer function developed by Jakobsson et al. (2000) is confirmed, and works extremely well under "background conditions", but can be easily overridden by depositional events, such as the grey layer.

- The Itrax Mn values can be reliably calibrated to Mn concentration using Mn measurements on bulk sediment, despite differences in spatial resolution.

- Post-depositional processes can be ruled out as the main factor controlling the formation of the Mn cycles.

- A combination of several lines of evidence suggest that the Mn cycles are indeed caused by changes in environmental conditions, notably water column ventilation and riverine input, and therefore correspond to interglacial-glacial variations. Consequently, where sedimentation rates do not preclude the preservation of these cycles, they should provide a useful tool by which cores from different parts of the Arctic Basin may be correlated.

Further avenues to investigate the Mn cycles and their environmental significance include studies of regional and local variability in the way the $\mathrm{Mn}$ cycles are expressed in the sediment, detailed studies of how bioturbation intensity and trace fossil fauna change around the Mn peaks, and detailed trace element and provenance studies comparing the sediment in the Mn cycles with the intervals where the Mn colour signal was overridden by other factors.

\section{References}

Anderson D.M. 2001. Attenuation of millennial-scale events by bioturbation in marine sediments. Paleoceanography 16 , 352-357.

Backman J., Moran K., McInroy D.B., Mayer L.A. \& the Expedition 302 Scientists 2006. Sites M0001-M0004. Proceedings of the Ocean Drilling Program. Scientific Results 302, doi:10.2204/iodp.proc.302.101.2006.
Berger W.H. \& Heath G.R. 1968. Vertical mixing in pelagic sediments. Journal of Marine Research 26, 134-143.

Burdige D. 2006. Geochemistry of marine sediments. Princeton, NJ: Princeton University Press.

Croudace I.W., Rindby A. \& Rothwell R.G. 2006. ITRAX: description and evaluation of a new multi-function X-ray core scanner. In R.G. Rothwell (ed.): New techniques in sediment core analysis. Pp. 51-63. London: Geological Society of London.

Dhakar S. \& Burdige D. 1996. A coupled, non-linear, steady-state model for early diagenetic processes in pelagic sediments. American Journal of Science 296, 296-330.

Dickens G.R., Koelling M., Smith D.C., Schnieders L. \& the IODP Expedition 302 Scientists 2007. Rhizon sampling of pore waters on Scientific Drilling Expeditions: an example from the IODP Expedition 302, Arctic Coring Expedition (ACEX). Scientific Drilling 4, doi:10.2204/iodp.sd.4.08.2007.

Finney B., Lyle M.W. \& Heath G.R. 1988. Sedimentation at MANOP site $\mathrm{H}$ (eastern equatorial Pacific) over the past 400000 years: climatically induced redox variations and their effects on transition metal cycling. Paleoceanography 3 , 169-189.

Forsström L. 2001. Duration of interglacials: a controversial question. Quaternary Science Reviews 20, 1577-1586.

Haschke M. 2006. The Eagle III BKA system, a novel sediment core X-ray fluorescence analyser with very high spatial resolution. In R.G. Rothwell (ed.): New techniques in sediment core analysis. Pp. 31-37. London: Geological Society of London.

Jakobsson M., Backman J., Murray A. \& Løvlie R. 2003. Optically stimulated luminescence dating supports central Arctic Ocean cm-scale sedimentation rates. Geochemistry, Geophysics, Geosystems 4, 1-11.

Jakobsson M., Løvlie R., Al-Hanbali H., Arnold E., Backman J. \& Mörth M. 2000. Manganese and color cycles in Arctic Ocean sediments constrain Pleistocene chronology. Geology 28, 23-26.

Jakobsson M., Løvlie R., Arnold E.M., Backman J., Polyak L., Knutsen J.-O. \& Musatov E. 2001. Pleistocene stratigraphy and paleoenvironmental variation from Lomonosov Ridge sediments, central Arctic Ocean. Global and Planetary Change 31, 1-22.

Lasaga A. \& Holland H. 1974. Mathematical aspects of non steady state diagenesis. Geochimica et Cosmochimica Acta 40, 257-266.

Li Y.-H., Bischoff J. \& Mathieu G. 1969. Migration of manganese in Arctic Basin sediment. Earth and Planetary Science Letters 7, 265-270.

Lisiecki L.E. \& Raymo M.E. 2005. A Pliocene-Pleistocene stack of 57 globally distributed benthic $\mathrm{d}^{18} \mathrm{O}$ records. Paleoceanography 20, doi:10.1029/2004PA001071.

Mangini A., Jung M. \& Laukenmann S. 2001. What do we learn from peaks of uranium and of manganese in deep sea sediments? Marine Geology 177, 63-78.

Polyak L., Edwards M.H., Coakley B.J. \& Jakobsson M. 2001. Ice shelves in the Pleistocene Arctic Ocean inferred from glaciogenic deep-sea bedforms. Nature 410, 453-459. 
Richter T.O., van der Gaast S., Koster B., Vaars A., Gieles R., de Stigter H.C., De Haas H. \& Van Weering T.C.E. 2006.

The Avaatech XRF core scanner: technical description and applications to NE Atlantic sediments. In R.G. Rothwell (ed.): New techniques in sediment core analysis. Pp. 39-50. London: Geological Society of London.

Schiffelbein P. 1984. Effect of benthic mixing on the information content of deep-sea stratigraphic signals. Nature 311, 651-653.

Spielhagen R.F., Baumann K.-H., Erlenkeuser H., Nowaczyk N.R., Nörgaard-Pedersen N., Vogt C. \& Weiel D. 2004. Arctic Ocean deep-sea record of northern Eurasian ice sheet history. Quaternary Science Reviews 23, 1455-1483.
Thomson J., Higgs N.C. \& Colley S. 1996. Diagenetic redistribution of redox-sensitive elements in NE Atlantic glacial/interglacial transition sediments. Earth and Planetary Science Letters 139, 365-377.

Tjallingii R., Röhl U., Kölling M. \& Bickert T. 2007. Influence of the water content on X-ray fluorescence core-scanning measurements in soft marine sediments. Geochemistry, Geophysics, Geosystems 8, Q02004, doi:10.1029/ 2006 GC001393.

Wilson T., Thomson J., Hydes D., Colley S., Culkin F. \& Sørensen J., 1986. Oxidation fronts in pelagic sediments: diagenetic formation of metal rich layers. Science 232, 972-975. 